\title{
REMOVAL OF METHYLENE BLUE BY ADSORPTION ONTO RETAMA RAETAM PLANT: KINETICS AND EQUILIBRIUM STUDY
}

\author{
Dalila Badis ${ }^{\mathrm{a}}$, Zoubir Benmaamar ${ }^{\mathrm{b} *}$, Othmane Benkortbi ${ }^{\mathrm{a}}$, Houcine Boutoumi ${ }^{\mathrm{c}}$, \\ Houria Hamitouche ${ }^{\mathrm{b}}$, Amele Aggoun ${ }^{\mathrm{c}}$
aiomaterials and Transport Phenomena Laboratory, University of Dr Yahia Fares, Ain d'hab, Medea 26000, Algeria
${ }^{b} H y d r o g e n$ Energetical Application Laboratory, University of Blida1, Soumaa, Blida 9000, Algeria
${ }^{c}$ Chemical Engineering Laboratory, University of Blida1, Soumaa, Blida 9000, Algeria
*e-mail: benmaamarzoubir@yahoo.fr

\begin{abstract}
The feasibility of using medicinal plants species Retama raetam as a low cost and an eco-friendly adsorbent for the adsorption of cationic dye methylene blue from simulated aqueous solution has been investigated. Adsorption kinetics of methylene blue onto Retama raetam plants was studied in a batch system. The effects of $\mathrm{pH}$ and contact time were examined. The methylene blue maximum adsorption occurred at $\mathrm{pH} 8$ and the lowest adsorption occurred at $\mathrm{pH} 2$. The apparent equilibrium was reached after $120 \mathrm{~min}$. Optimal experimental conditions were determined. Adsorption modelling parameters for Freundlich and Langmuir isotherms were determined and, based on $\mathrm{R}^{2}$, various error distribution functions were evaluated as well. Adsorption isotherm was best described by non linear Freundlich isotherm model. Thermodynamic studies show that adsorption was spontaneous and exothermic. For determining the best-fit-kinetic adsorption model, the experimental data were analyzed by using pseudo-first-order, pseudo-second-order, pseudo-third-order, Esquivel, and Elovich models. Linear regressive and non-linear regressive method was used to obtain the relative parameters. The statistical functions were estimated to find the suitable method that fit better the experimental data. Both methods were appropriate for obtaining the parameters. The linear pseudo-second-order (type 9 and type 10) models were the best to fit the equilibrium data. The present work showed that plant Retama raetam can be used as a low cost adsorbent for the removal of methylene blue from water.
\end{abstract}

Keywords: Retama raetam, methylene blue, removal, modelling, adsorption.

Received: June 2016/ Revised final: November 2016/ Accepted: November 2016

\section{Introduction}

The textile industry is one of industrial waste water source. This contaminated water is very toxic for the humans and animals [1]. Methylene blue is used in colouring paper, dyeing cottons, wools, silk, leather and coating for paper stock. Although methylene blue is not strongly hazardous, it can cause some harmful effects, such as heartbeat increase, vomiting, shock, cyanosis, jaundice, quadriplegia, and tissue necrosis in human organisms [2].

Chemical coagulation-flocculation [3], different types of oxidation processes [4], biological process [5], membrane-based separation processes [6] and adsorption [7] were the treatments used in the purification of waters. The most efficient method used for the quickly removal of dyes from the aqueous solution is the physical adsorption [8]. Biosorbents, such as wood sawdust [9], waste-biomass [10], delonix regia [11], agricultural solid waste [12], are able to remove efficiently the colour from water.

Retama raetam plants can be used as biosorbent. This species belonging to the Fabaceae family has a very productive vertical and horizontal root system, which can reach $20 \mathrm{~m}$. This, in turn, increases substantially the stabilization of the soil. Moreover, the Retama species contributes to the biofertilisation of poor grounds, because of their aptitude to associate with fixing nitrogen bacteria Rhizobia. Therefore, the genus of Retama is included in a re-vegetation program for degraded areas in semi-arid Mediterranean environments [13].

Retama raetam is a common plant in the North African and East Mediterranean region. In Algeria, it is located in Sahara and Atlas regions and is used in folk medicine under the common name "R'tam" to reduce the blood glucose and skin inflammations, while in Lebanon it is used as folk herbal medicine against joint aches and in Morocco against skin diseases. Previous pharmacological studies on the plant have revealed its various medicinal properties: antibacterial, antifungal, antihypertensive, antioxidant, antiviral, diuretic, hypoglycaemic, hepatoprotective, nephroprotective and cytotoxic effects. Retama species have been reported to contain flavonoids and alkaloids [14].

However, there are no reported studies on the adsorption of cationic dyes by Retama raetam. This work aims to understand the potential of Retama raetam for removal of methylene blue dye from simulated aqueous solution in batch mode. The adsorption efficiency of methylene blue was investigated in order to optimize the experimental parameters. The statistical functions were used to estimate the error deviations between experimental and theoretically predicted adsorption values, including linear and non-linear method. The optimization procedure required a defined error function in order to evaluate the fit of equation to the experimental data. 


\section{Experimental \\ Materials}

Methylene blue (3,7-bis (Dimethylamino)-phenazathionium chloride tetramethylthionine chloride, $\mathrm{C}_{16} \mathrm{H}_{18} \mathrm{~N}_{3} \mathrm{SCl} \cdot 3 \mathrm{H}_{2} \mathrm{O}, \mathrm{Mw}=373.9 \mathrm{~g} / \mathrm{mol}$, Figure 1) used in the present study was purchased from Merck (Germany), being selected from the list of dyes normally used in Algeria. Retama raetam plants were collected in Mostaganem region (Algeria), washed several times with deionized water to remove the color and dried at $105^{\circ} \mathrm{C}$ for $5 \mathrm{~h}$ in a convection oven. The residual organics and lipids were respectively removed by methanol and petroleum ether. After this procedure, Retama raetam was washed again with distilled water.<smiles></smiles>

Figure 1. Structure of methylene blue [15].

\section{Methods}

The Retama raetam was characterized by $\mathrm{pH}$ measurement of the $\mathrm{pH}_{\mathrm{PZC}}$ (point of zero charge). The $\mathrm{pH}_{\mathrm{PZC}}$ of an adsorbent is a very important characteristic that determines the $\mathrm{pH}$, at which the adsorbent surface has net electrical neutrality [16].

The $\mathrm{pH}_{\mathrm{PZC}}$ of Retama raetam was measured by $\mathrm{pH}$ drift method: $0.1 \mathrm{mg}$ of Retama raetam is added to $100 \mathrm{~mL}$ of water with varying $\mathrm{pH}$ from 2 to 12 and stirred for $24 \mathrm{~h}$. Final $\mathrm{pH}$ of the solution is plotted against initial $\mathrm{pH}$ of the solution and shown in Figure 2 [17]. The value of $\mathrm{pH}_{\mathrm{PZC}}$ for Retama raetam was determined as $\mathrm{pH} 6$.

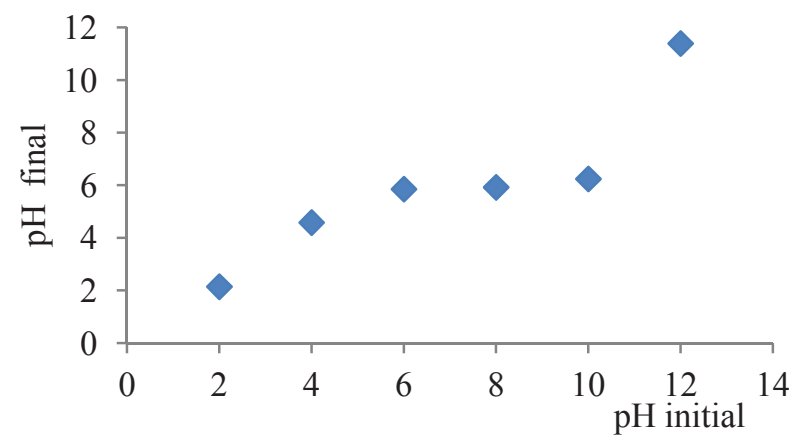

Figure 2. Point of zero charge $\left(\mathrm{pH}_{\mathrm{pzC}}\right)$ of the Retama raetam used for the adsorption experiments.

Adsorption isotherms are important for the description of how adsorbates interact with an adsorbent being also critical in optimizing the use of adsorbent. Thus, the correlation of equilibrium data using either a theoretical or empirical equation is essential for interpretation of the adsorption data and prediction, as well. Several mathematical models can be used to describe experimental data of adsorption isotherms. Two famous isotherm equations, the Langmuir and Freundlich, were employed for further interpretation of the obtained adsorption data.

Adsorption kinetics of methylene blue onto Retama raetam was studied in a batch system. The effects of $\mathrm{pH}$ and equilibrium time were examined. The adsorption parameters were optimized. In each experiment pre weighed amount of adsorbent $(0.04 \mathrm{~g})$ was added to $200 \mathrm{~mL}$ of dye solution $(20 \mathrm{mg} / \mathrm{L})$ taken in a conical flask of $250 \mathrm{~mL}$ and $0.1 \mathrm{M} \mathrm{NaOH}$ or $0.1 \mathrm{M} \mathrm{HCl}$ were added to adjust the $\mathrm{pH}$ value. This solution was agitated at $300 \mathrm{rpm}$ and centrifuged. The methylene blue concentration in solution was determined at $\lambda_{\max }=665 \mathrm{~nm}$ by using UV-1700 PHARMA SPEC SHIMADZU spectrophotometer. The adsorbed amount of methylene blue per mass unit of adsorbent at time $t, q(\mathrm{mg} / \mathrm{g})$, (Eq.(1)) and the dye removal efficiency $(R, \%)($ Eq.(2)) were calculated as:

$$
\begin{aligned}
& q=\left(C_{0}-C\right) \frac{V}{M} \\
& R=\frac{\left(C_{0}-C\right)}{C_{0}} \times 100
\end{aligned}
$$

where $C_{0}$ is the initial concentration of methylene blue $(\mathrm{mg} / \mathrm{L}), C$ is the dye concentration at time $t, V$ is the solution volume (L) and $M$ is the adsorbent mass $(\mathrm{g})[18]$. 
The effect of $\mathrm{pH}$ was evaluated by mixing $0.2 \mathrm{~g}$ of adsorbent with $1 \mathrm{~L}$ of methylene blue simulated aqueous solution of $20 \mathrm{mg} / \mathrm{L}$. The $\mathrm{pH}$ value of solution was varied from 2 to 13 , by adding $0.1 \mathrm{M} \mathrm{NaOH}$ or $0.1 \mathrm{M} \mathrm{HCl}$ solutions. The suspension was shaken for $24 \mathrm{~h}$ at $25^{\circ} \mathrm{C}$.

Kinetic experiments were performed by mixing $200 \mathrm{~mL}$ of dye solution $(20 \mathrm{mg} / \mathrm{L})$ with $0.04 \mathrm{~g}$ of adsorbent for different time $(5,10,30,60,90,120,150$, and $180 \mathrm{~min})$. The initial $\mathrm{pH}$ for each dye solution was set at 8 . Methylene blue concentration in the supernatants was determined and the adsorbed amount of methylene blue was calculated.

\section{Results and discussion}

For studying the effect of every parameter, it is necessary to fix the values of other ones. The elimination of pollutant from simulated aqueous solution by adsorption is extremely influenced by the medium of solution, which affects the nature of the adsorbent surface charge, the ionization extent, the aqueous adsorbate species speciation and the adsorption rate. The adsorptive process through functional groups dissociation on the adsorbate and adsorbent were affected by a $\mathrm{pH}$ change [19]. The adsorption of methylene blue augments with increasing the $\mathrm{pH}$ of the solution. According to the data presented in Figure 3, the best value of adsorption capacity, $q_{e}=9.938 \mathrm{mg} / \mathrm{g}$, was recorded at $\mathrm{pH} 8$. From this study, it is obvious that in the basic medium, the negatively charged species tend to dominate leading to a more negatively charged surface. In this case, the adsorbent surface is negatively charged. The methylene blue adsorption increases due to the enhancement of electrostatic attractions between the negative charge of Retama raetam particles and the positive charge of methylene blue species.

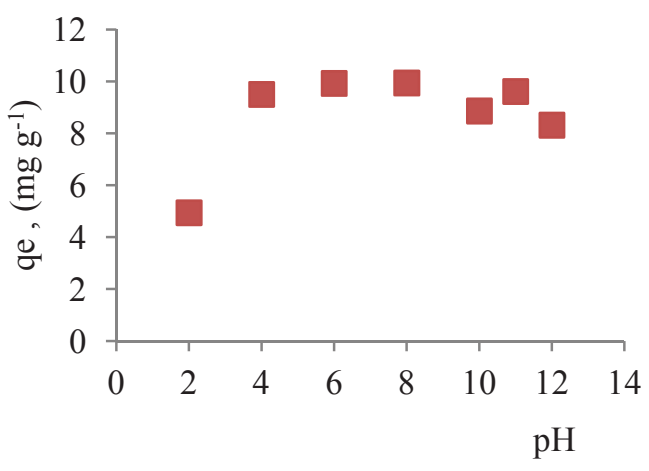

Figure 3. Effect of the initial pH of solution on equilibrium adsorption capacity of Retama raetam.

The experimental data for methylene blue adsorption on Retama raetam were analyzed with the Freundlich and Langmuir equations. Equations of these models [20] are presented in Table 1, where $q$ is the equilibrium dye concentration on adsorbent $(\mathrm{mg} / \mathrm{g}), q_{m}$ is the monolayer capacity of the adsorbent $(\mathrm{mg} / \mathrm{g}), C$ is the equilibrium dye concentration in solution $(\mathrm{mg} / \mathrm{L}), K_{L}$ is the Langmuir adsorption constant representing the energy constant related to the heat of adsorption, $n$ and $K_{F}$ are Freundlich constants related to adsorption intensity of the adsorbent and adsorption. A non-linear and linear fitting procedure using Excel and Origin software were used, respectively. The constants of all models were given in Table 2 .

Adsorption isotherms models and their linear and non linear forms [20].

Table 1

\begin{tabular}{ccc}
\hline Applied model & Non linear form & Linear form \\
\hline Langmuir & $\frac{q}{q_{m}}=\frac{K_{L} C}{1+K_{L} C}$ & $\frac{C}{q}=\frac{C}{q_{m}}+\frac{1}{k_{L} q_{m}}$ \\
Freundlich & $q=K_{F} C^{1 / n}$ & $\ln (q)=\ln \left(k_{F}\right)+n \ln (C)$ \\
\hline
\end{tabular}

The coefficient of correlation indicated that Freundlich isotherm fitted the experimental data better than Langmuir isotherm. Good agreement between the experimental isotherms and the Freundlich model was found in the case of systems: pentachlorophenol/(M)Al-MCM-41 [21], and toluene/activated carbon [22].

The optimization procedure required a defined error function in order to evaluate the fit of equation to the experimental data. The best-fitting equation is determined using the well-known special functions to calculate the error deviation between experimental and predicted data. The mathematical equations of these error functions were illustrated in Table 3. 
Constants for linear and non-linear Langmuir and Freundlich isotherms related to the adsorption of methylene blue onto Retama raetam.

\begin{tabular}{ccc}
\hline Model & Linear method & Non-linear method \\
\hline Langmuir model & & \\
$q_{m}$ & $-142.857<0$ & $3.986 \cdot 10^{+6}$ \\
$K_{1}$ & $-0.350<0$ & $4.811 \cdot 10^{-44}$ \\
$R^{2}$ & 0.609 & 0.799 \\
Freundlich model & & \\
$k_{F}$ & 115.353 & 96.837 \\
$n$ & 1.806 & 0.483 \\
$R^{2}$ & 0.989 & 0.967 \\
\hline
\end{tabular}

Mathematical equations of error functions.

Table 3

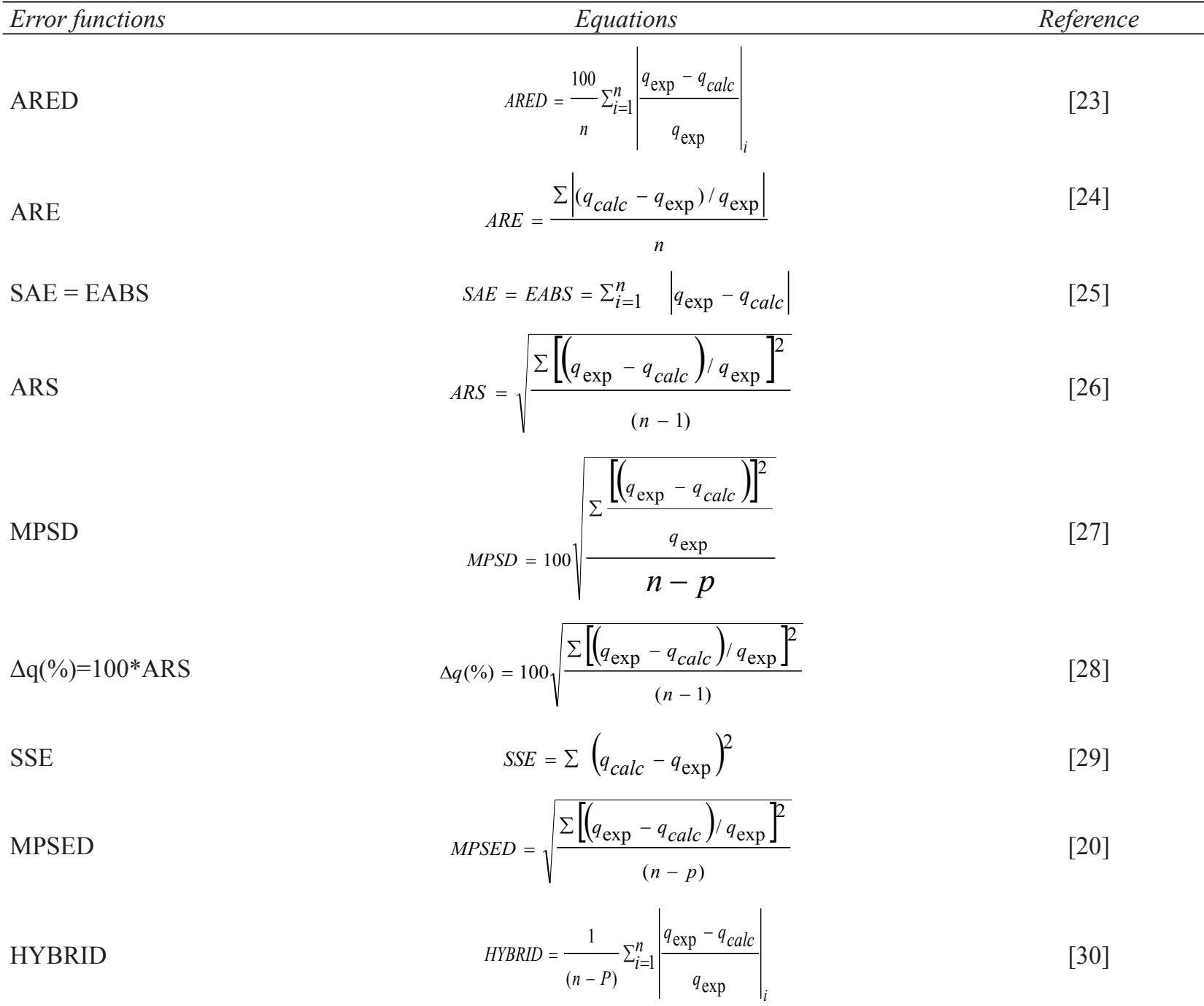

where $n$ is the number of experimental data points, $q_{\text {calc }}$ is the predicted (calculated) quantity of methylene blue adsorbed onto Retama raetam, $q_{\exp }$ is the experimental data, $\mathrm{p}$ is the number of parameters in each kinetic model, $A R E D$ is the average relative error deviation (dimensionless parameter), $A R E$ is the average relative error (dimensionless parameter), $A R S$ is the average relative standard error (dimensionless parameter), HYBRID is the hybrid fractional error function (dimensionless parameter), MPSD Marquardt's is the percent standard deviation (dimensionless parameter), MPSED Marquardt's is the percent standard deviation (dimensionless parameter), $S A E=E A B S$ is the sum of absolute error $(\mathrm{mg} / \mathrm{g}), S S E$ is the sum of the squares of the errors $(\mathrm{mg} / \mathrm{g})^{2}$, and $\Delta q(\%)$ is the normalized standard deviation $(\mathrm{mg} / \mathrm{g})$. The constants of all error analysis are represented in Table 4. 
Error deviation data related to the adsorption of methylene blue onto Retama raetam employing the most commonly used functions.

\begin{tabular}{|c|c|c|c|c|c|c|c|c|c|}
\hline 这造 & 国 & 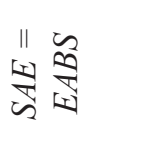 & 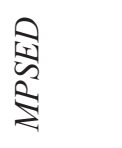 & 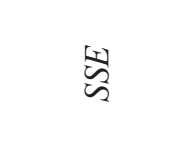 & 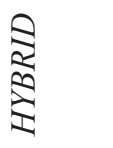 & $\underset{⿱ 亠 乂}{2}$ & $\stackrel{F}{\gtrless}$ & 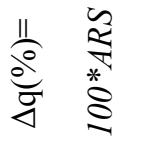 & \begin{tabular}{l}
$\hat{\Sigma}$ \\
\multirow{z}{z}{}
\end{tabular} \\
\hline $\begin{array}{c}\text { Linear Freundlich } \\
\text { model }\end{array}$ & 113.162 & 1064.355 & 1.966 & 313447.05 & 1.383 & 1.131 & 1.865 & 186.493 & 1051.57 \\
\hline $\begin{array}{c}\text { Non Linear } \\
\text { Freundlich model }\end{array}$ & 22.899 & 277.32 & 0.285 & 13850.819 & 0.28 & 0.229 & 0.27 & 27.028 & 254.777 \\
\hline
\end{tabular}

The data of adsorption isotherm are essentially required for designing the adsorption systems. In order to optimize the design of a specific sorbate/sorbent system for removal of methylene blue from aqueous solution, it is important to establish the most appropriate correlation for the experimental kinetic data. Applicability of some statistical tools to predict the optimum adsorption isotherms of methylene blue onto Retama raetam after linear regression analysis showed that the highest $R^{2}$ value and the lowest ARED, ARE, SAE, ARS, MPSD, $\triangle q$, SSE, MSPED and HYBRID values can be suitable and meaningful tools to predict the best-fitting equation models.

The best fitting is determined based on the use of these functions for calculation of the error deviation between experimental and predicted equilibrium adsorption isotherm data, after linear analysis. Hence, according to Table 4, it seems that the linear Freundlich model was the most suitable mode to describe satisfactorily the studied adsorption phenomenon. Therefore, based on the mentioned results, the best useful error estimation statistical tools point out the non linear Freundlich model, followed by linear Freundlich model, as the best-fitting models.

In order to better understand the effect of temperature on the adsorption of methylene blue onto Retama raetam, the free energy change $\left(\Delta G^{\circ}, \mathrm{J} \mathrm{mol}^{-1}\right)$, enthalpy change $\left(\Delta H^{\circ}, \mathrm{J} \mathrm{mol}^{-1}\right)$ and entropy change $\left(\Delta S^{\circ}, \mathrm{J} \mathrm{K}^{-1} \mathrm{~mol}^{-1}\right) \mathrm{were}^{-}$ determined (such parameters reflect the feasibility and spontaneous nature of the process) using Eqs.(3)-(5).

$$
\begin{aligned}
& \Delta G^{\circ}=\Delta H^{\circ}-T \Delta S^{\circ} \\
& \Delta G^{\circ}=-R T L n\left(K_{c}\right)
\end{aligned}
$$

The combination of Eqs.(3) and (4) gives Eq.(5):

$$
\operatorname{Ln}\left(K_{c}\right)=\frac{\Delta S^{\circ}}{R}-\frac{\Delta H^{\circ}}{R T} \frac{1}{T}
$$

where $R$ is the universal gas constant $\left(8.314 \mathrm{~J} \mathrm{~K}^{-1} \mathrm{~mol}^{-1}\right), T$ is the absolute temperature (Kelvin) [31]. Experiments were performed using $20 \mathrm{mg} / \mathrm{L}$ dye solutions with $0.2 \mathrm{~g}$ of Retama raetam for $24 \mathrm{~h}$ at various temperatures. The apparent equilibrium constant $K_{c}$ of the adsorption is defined as Eq.(6) [20]:

$$
K_{c}=\frac{\left(C_{o}-C_{e}\right)}{C_{e}} \frac{V}{M}=\frac{q_{e}}{C_{e}}
$$

The enthalpy and entropy can be obtained from the slope and intercept of the linear plot of $\ln K_{c}$ versus $1 / T$. The

\begin{tabular}{|c|c|c|c|c|c|c|}
\hline & \multicolumn{6}{|c|}{ Temperature $(K)$} \\
\hline & 293 & 303 & 323 & 333 & 343 & 363 \\
\hline$K_{c}(\mathrm{~L} / \mathrm{mol})$ & $5.174 \cdot 10^{5}$ & $3.204 \cdot 10^{5}$ & $1.150 \cdot 10^{5}$ & $0.729 \cdot 10^{5}$ & $0.435 \cdot 10^{5}$ & $0.134 \cdot 10^{5}$ \\
\hline$\Delta G^{c}\left(\mathrm{~kJ} \mathrm{~mol}^{-1}\right)$ & -26.744 & -26.117 & -24.863 & -24.237 & -23.610 & -22.356 \\
\hline$\Delta H^{\circ}\left(\mathrm{kJ} \mathrm{mol}^{-1}\right)$ & \multicolumn{6}{|c|}{$-4.511 \cdot 10^{5}$} \\
\hline$\Delta S^{\circ}\left(\mathrm{J} \mathrm{K}^{-1} \mathrm{~mol}^{-1}\right)$ & \multicolumn{6}{|c|}{-62.687} \\
\hline$R^{2}$ & \multicolumn{6}{|c|}{0.989} \\
\hline
\end{tabular}
obtained thermodynamic parameters are given in Table 5.

Table 5

Calculated thermodynamic parameters for adsorption of methylene blue onto Retama raetam. 
A negative enthalpy value of $-4.511 \cdot 10^{5} \mathrm{~kJ} / \mathrm{mol}$ indicates that adsorption was exothermic. A negative entropy value of $-62.687 \mathrm{~J} / \mathrm{mol}$ and a negatively decreasing Gibbs free energy indicates the increase in the randomness in the solid-liquid interface and adsorption spontaneity [32].

Figure 4 illustrates the effect of contact time on decolorization (dye adsorption) with Retama raetam. The plot (simulated aqueous solution) can be divided in three zones: (i) 0-30 min, which indicate the fast adsorption of methylene blue, suggesting a rapid external diffusion and surface adsorption; (ii) 30-60 min, show a gradual equilibrium, and (iii) 60-180 min, indicate the plateau of the equilibrium state. The adsorption was rapid at the initial stage of the contact, but it gradually slowed down until the equilibrium. The fast adsorption at the initial stage can be attributed to the fact that a large number of surface sites are available for adsorption. After a lapse of time, the remaining surface sites are difficult to be occupied.

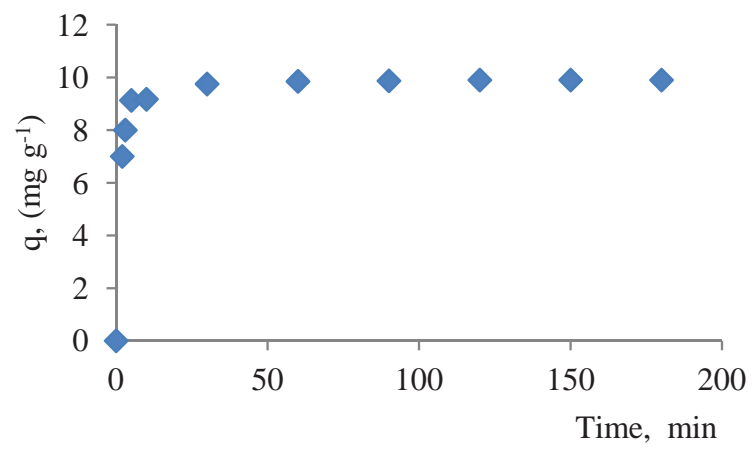

Figure 4. Adsorption kinetics of methylene blue on Retama raetam.

Adsorption is a complex process that is influenced by several parameters related to adsorbent and to the physicochemical conditions, under which the process is carried out [33]. For understanding the mechanism of the adsorption process, the following equations: pseudo-first order (Lagergren Model) [2], pseudo-second order [34], Esquivel [35], pseudo-third order [36], and Elovich [37] were selected to fit the experimental kinetic data. Equations of these models are presented in Table 6.

Table 6

Adsorption kinetics models and their linear and non linear forms.

\begin{tabular}{|c|c|c|c|}
\hline Applied model & Non Linear form & Linear form & Reference \\
\hline \multicolumn{4}{|c|}{ Pseudo-first order } \\
\hline Pseudo-first order (type 1) & $q=q_{e}\left(1-e^{-k_{1} t}\right)$ & $\log \left(q_{e}-q\right)-\log \left(q_{e}\right)=-\frac{k_{1} t}{2.303}$ & [38] \\
\hline \multicolumn{4}{|c|}{ Pseudo-second order } \\
\hline Pseudo-second order (type 9) & & $\frac{q_{e}}{q_{e}-q}-1=k_{2} t$ & [39] \\
\hline Pseudo-second order (type 10) & $q=q_{e}\left[1-\frac{1}{1+k_{2} t}\right]$ & $\frac{\theta}{1-\theta}=k_{2} t$ & [39] \\
\hline Esquivel model (type 1) & $q=q_{e}\left(\frac{t}{t+K_{E}}\right)$ & $\frac{1}{q}=\left(\frac{K_{E}}{q_{e}}\right) \frac{1}{t}+\frac{1}{q_{e}}$ & [35] \\
\hline Esquivel model (type 2) & $q=q_{e}\left(\frac{t}{t+K_{E}}\right)$ & $\left(\frac{1}{q}-\frac{1}{q_{e}}\right) q_{e}=K_{E} \frac{1}{t}$ & [35] \\
\hline Elovich (type1) & $\frac{d q}{d t}=k_{4} \exp \left(-k_{5} q\right)$ & $q=k_{5} \ln \left(k_{5} k_{4}\right)+k_{5} \ln (t)$ & [37] \\
\hline Elovich (Roginsky-Zeldovich) (type 2) & $\frac{a q}{d t}=k_{7} \exp \left(k_{6} q\right)$ & $q=\left(1 / k_{6}\right) \ln \left(k_{6} k_{7}\right)+\left(1 / k_{6}\right) \ln (t)$ & {$[40]$} \\
\hline
\end{tabular}

where $k_{1}$ is pseudo-first order rate constant $\left(\mathrm{min}^{-1}\right), k_{2}$ is pseudo-second order rate constant $(\mathrm{g} /(\mathrm{mg} \min ))$ $k_{3}$ is pseudo-third order rate constant $\left(\mathrm{g}^{2} /\left(\mathrm{mg}^{2} \mathrm{~min}\right)\right), K_{E}$ is Esquivel rate constant (min), $k_{4}$ is Elovich rate constant $(\mathrm{mg} /(\mathrm{g} \mathrm{min})), k_{5}$ is extent of surface coverage and activation energy of the process $(\mathrm{g} / \mathrm{mg}), k_{6}$ is extent of surface coverage and activation energy of the process $(\mathrm{g} / \mathrm{mg}), k_{7}$ is Elovich rate constant $(\mathrm{mg} /(\mathrm{g}$ min $)), q$ is amount of adsorption at equilibrium $(\mathrm{mg} / \mathrm{g})$, and $\theta$ is dimensionless parameter $\left(=q / q_{e}\right)$. For the non-linear and linear fitting procedures Excel and Origin software were used, respectively. The constants of all models were given in Table 7. 
Kinetics constants related to the adsorption of methylene blue onto Retama raetam.

\begin{tabular}{|c|c|c|}
\hline Model & Linear Method & Non-linear Method \\
\hline \multicolumn{2}{|c|}{ Pseudo-first order (type 1) } & Non-linear Pseudo-first order (type 1) \\
\hline$q_{e}$ & 9.900 & 9.782 \\
\hline$K_{1}$ & 0.403 & 0.517 \\
\hline$R^{2}$ & 0.854 & 0.996 \\
\hline Equation & $\log (\mathrm{qe}-\mathrm{q})-\log (\mathrm{qe})=-0.175 * \mathrm{t}$ & $\mathrm{q}=9.782 *(1-\exp (-0.517 * \mathrm{t}))$ \\
\hline \multicolumn{3}{|c|}{ Pseudo-second order (type 9) } \\
\hline$q_{e}$ & 9.932 & \multirow{9}{*}{$\begin{array}{c}9.908 \\
1.97 \\
0.999 \\
\mathrm{q}=9.908 *(1-(1 /(1+1.97 * t)))\end{array}$} \\
\hline$K_{2}$ & 1.926 & \\
\hline$R^{2}$ & 0.946 & \\
\hline Equation & $(\mathrm{qe} /(\mathrm{qe}-\mathrm{q}))-1=1.926 * \mathrm{t}$ & \\
\hline \multicolumn{2}{|c|}{ Pseudo-second order (type 10) } & \\
\hline$q_{e}$ & 9.933 & \\
\hline$K_{2}$ & 1.926 & \\
\hline$R^{2}$ & 0.946 & \\
\hline Equation & $(\theta /(1-\theta))=1.926^{*} \mathrm{t}$ & \\
\hline \multicolumn{3}{|c|}{ Esquivel Model (type 1) } \\
\hline$q_{e}$ & 9.901 & \multirow{9}{*}{$\begin{array}{c}9.908 \\
0.507 \\
0.999 \\
\mathrm{q}=9.908 *(\mathrm{t} /(\mathrm{t}+0.507))\end{array}$} \\
\hline$K_{E}$ & 0.485 & \\
\hline$R^{2}$ & 0.874 & \\
\hline Equation & $1 / \mathrm{q}=0.049 *(1 / \mathrm{t})+0.101$ & \\
\hline \multicolumn{2}{|c|}{ Esquivel Model (type 2) } & \\
\hline$q_{e}$ & 9.900 & \\
\hline$K_{E}$ & 0.492 & \\
\hline$R^{2}$ & 0.874 & \\
\hline Equation & $(((1 / q)-(1 / q)) * q e)=0.492 *(1 / t)$ & \\
\hline \multicolumn{3}{|c|}{ Elovich (type 1) } \\
\hline$K_{4}$ & $2.91310^{+16}$ & \\
\hline$K_{5}$ & 0.240 & \\
\hline$R^{2}$ & 0.899 & \\
\hline Equation & $\mathrm{q}=0.240 * \ln (\mathrm{t})+8.756$ & \\
\hline \multicolumn{3}{|c|}{ Elovich (type 2) } \\
\hline$K_{4}$ & $1.67810^{+5}$ & \\
\hline$K_{5}$ & 4.167 & \\
\hline$R^{2}$ & 0.899 & \\
\hline Equation & $\mathrm{q}=0.240 * \ln (\mathrm{t})+8.756$ & \\
\hline
\end{tabular}

Table 7 shows that $q_{e}, k_{2}$ and $R^{2}$ values obtained from the two linear forms of pseudo-secondorder expressions were the same. The value of $q_{e}$ and $k_{2}$ were calculated to be, respectively, $9.932 \mathrm{mg} \mathrm{g}^{-1}$ and $1.926 \mathrm{~g} \mathrm{mg}^{-1} \mathrm{~min}^{-1}$ for linear pseudo-second-order and $9.908 \mathrm{mg} \mathrm{g}^{-1}$ and $1.97 \mathrm{~g} \mathrm{mg}^{-1} \mathrm{~min}^{-1}$ for non linear pseudo-second order biosorption. The constants of all error analysis are represented in Table 8.

Adsorption kinetic data are the basic requirements for the design of adsorption systems. In order to optimize the design of a specific sorbate/sorbent system to remove methylene blue from aqueous solution, it is important to establish the most appropriate correlation for the experimental kinetic data. Applicability of some statistical tools to predict optimum adsorption kinetics of methylene blue onto Retama raetam after linear regression analysis showed that the highest $\mathrm{R}^{2}$ value and the lowest ARED, ARE, SAE, ARS, MPSD, $\triangle q$, SSE, MSPED, and HYBRID values could be suitable and meaningful tools to predict the best-fitting equation models.

The best fitting is determined based on the use of these functions to calculate the error deviation between experimental and predicted equilibrium adsorption kinetic data, after linear analysis. Hence, according to Table 4, it seems that the linear pseudo- second order type 9 and type 10 models were the most suitable models to describe satisfactorily the studied adsorption phenomenon. Therefore, based on these mentioned results, the best useful error estimation statistical tools should point out the linear pseudo- second order type 9 followed by linear pseudo- second order type 10 as the best-fitting models. 
In the most studied adsorption systems, the pseudo-first-order model does not fit well over the entire adsorption period and is generally applicable over the first 20-30 min of the sorption process. The pseudo-second-order model is based on the biosorption capacity of the solid phase and it generally predicts the "chemisorption" behaviour over the whole time of adsorption [20].

Obtained results, presented in Table 4 show that the pseudo-first-order model data do not fall on straight lines indicating that this model was less appropriate. In contrast, the pseudo second order kinetics have shown very low $A R E D, A R E$, SAE, ARS, MPSD, $\triangle q$, SSE, MSPED, and HYBRID and high $\mathrm{R}^{2}$ values for type 9, 10 linear pseudo-secondorder, and non linear pseudo-second-order expressions suggest that it is appropriate to use the pseudo-second-order model, suggesting that it is applicable to the adsorption kinetics. This suggests that, the biosorption of methylene blue onto Retama raetam is a chemisorption process involving exchange or sharing of electrons mainly between the dye ions and the sorbent functional groups [20]. Using linear method it was found that a theoretical pseudo-second order model represents well the experimental kinetic data of adsorption of methylene blue onto Retama raetam based on a Type 9 and 10 pseudo-second-order kinetic expression.

Studies regarding the use of Retama raetam as biosorbent are in progress. More technical and experimental optimisations and treatments should be realised to improve the adsorption capacity of Retama raetam. For example, use of more effective pre-treatment methods and reduction in particle size (larger specific adsorption area, $\mathrm{m}^{2} / \mathrm{g}$ ) may further improve the rate and the extent of adsorption of methylene blue onto Retama raetam. Besides, the methylene blue -loaded biomass itself has to be treated, in order to avoid a pollution transfer. Indeed, one of the more common questions aroused by biosorption processes involves the fate of the biosorbent after the process. Care must be taken that solving one problem, not to create another. The sorbed methylene blue can be recovered by extraction from the biomass in order to be concentrated and then stored, reused, or eliminated. Also, the decontamination of the methylene blue -loaded biomass by biodegradation is a very interesting approach.

Table 8

Error deviation data related to the methylene blue adsorption onto Retama raetam employing most commonly used functions.

\begin{tabular}{|c|c|c|c|c|c|c|c|c|c|}
\hline 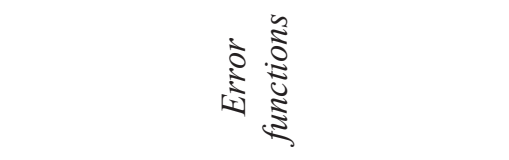 & 这 & 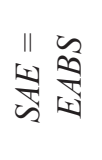 & 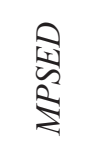 & 呫 & 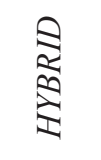 & $\frac{1}{2}$ & $\stackrel{\gtrless}{\gtrless}$ & 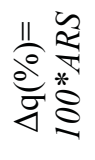 & $\stackrel{\vartheta}{\xi}$ \\
\hline Linear Pseudo-first order type 1 & 1.801 & 1.334 & 0.035 & 0.635 & 0.024 & 0.018 & 0.033 & 3.283 & 10.741 \\
\hline $\begin{array}{c}\text { Non Linear Pseudo-first order } \\
\text { type } 1\end{array}$ & 1.561 & 1.184 & 0.027 & 0.372 & 0.021 & 0.015 & 0.025 & 2.488 & 8.179 \\
\hline Linear pseudo- second order type 9 & 0.599 & 0.442 & 0.013 & 0.092 & 0.008 & 0.006 & 0.012 & 1.251 & 4.090 \\
\hline $\begin{array}{c}\text { Linear pseudo- second order } \\
\text { type } 10\end{array}$ & 0.599 & 0.442 & 0.013 & 0.092 & 0.008 & 0.006 & 0.012 & 1.251 & 4.090 \\
\hline $\begin{array}{c}\text { Non linear pseudo- second order } \\
\text { type } 1\end{array}$ & 0.701 & 0.523 & 0.013 & 0.088 & 0.009 & 0.007 & 0.012 & 1.225 & 4.012 \\
\hline $\begin{array}{c}\text { Linear Esquivel } \\
\text { type } 1\end{array}$ & 0.708 & 0.530 & 0.013 & 0.090 & 0.009 & 0.007 & 0.012 & 1.232 & 4.036 \\
\hline Linear Esquivel type 2 & 0.729 & 0.546 & 0.013 & 0.089 & 0.009 & 0.007 & 0.012 & 1.227 & 4.022 \\
\hline Non linear Esquivel & 0.700 & 0.522 & 0.013 & 0.088 & 0.009 & 0.007 & 0.012 & 1.225 & 4.012 \\
\hline Linear Elovich model type 1 & 0.827 & 0.64 & 0.012 & 0.078 & 0.011 & 0.008 & 0.011 & 1.098 & 3.682 \\
\hline Linear Elovich model type 2 & 0.827 & 0.64 & 0.012 & 0.078 & 0.011 & 0.008 & 0.011 & 1.098 & 3.682 \\
\hline
\end{tabular}

\section{Conclusions}

Retama raetam plant was used for the adsorption of methylene blue in simulated aqueous solution. In batch mode, the adsorption was highly dependent on two operating parameters ( $\mathrm{pH}$, contact time). The obtained results revealed the following optimal conditions: $\mathrm{pH}$ value of 8 and 120 min of contact time, which lead to $90.38 \%$ methylene blue removal.

Kinetics data correlated well with the pseudo second order kinetic model (type 9 and type 10), whereas equilibrium study was best described by non linear Freundlich isotherm model.

The adsorption kinetics of methylene blue onto Retama raetam can be better fitted by the pseudo- second order linear model (type 9 and type 10), as compared to the non-linear pseudo-second-order model, linear pseudo-secondorder model, pseudo first order, pseudo third order, and Esquivel models. The entire experimental results showed that Retama raetam is suitable adsorbent for the removal of methylene blue. 
The thermodynamic parameters such as: Gibbs free energy change $\Delta G^{\circ}$, standard enthalpy $\Delta H^{\circ}$, and standard entropy $\Delta S^{\circ}$ indicated that methylene blue adsorption onto Retama raetam was exothermic and spontaneous.

This study identified Retama raetam - at its raw state and without any physical or chemical activation - as a suitable low cost adsorbent to be used for removal of methylene blue dye from aqueous solution. The very rapid adsorption and high uptake capacity for methylene blue (62.5 to $91.33 \%$ removal rate in less than 4 minutes) make the Retama raetam a quite interesting alternative to more expensive materials such as activated carbons.

\section{References}

1. Shen, K.; Gondal, M.A. Removal of hazardous rhodamine dye from water by adsorption onto exhausted coffee ground. Journal of Saudi Chemical Society, 2013, doi:10.1016/j.jscs.2013.11.005.

2. Kushwaha, A.K.; Gupta, N.; Chattopadhyaya, M.C. Removal of cationic methylene blue and malachite green dyes from aqueous solution by waste materials of Daucus carota. Journal of Saudi Chemical Society, 2014, 18, pp. 200-207.

3. Prakash, N.B.; Sockan, V.; Jayakaran, P. Waste water treatment by coagulation and flocculation. International Journal of Engineering Science and Innovative Technology, 2014, 3(2), pp 479-484.

4. Petrovic, M.; Rarjenovic, J.; Barcelo, D. Advanced oxidation processes (AOPs): applied for wastewater and drinking water treatment. Elimination of pharmaceuticals. The Holistic Approach to Environment, 2011, 1(2), pp. 63-74.

5. Cesaro, A.; Naddeo, V.; Belgiorno, V. Wastewater Treatment by combination of advanced oxidation processes and conventional biological systems. Journal of Bioremediation and Biodegradation, 2013, 4(8), pp. 1-8.

6. Prince, J. A.; Bhuvana, S.; Anbharasi, V.; Ayyanar, N.; Boodhoo, K.V.; Singh, G. Self-cleaning metal organic framework (MOF) based ultra filtration membranes - A solution to bio-fouling in membrane separation processes. Scientific reports, 2014, 4, Article number: 65555, doi:10.1038/srep06555.

7. Abdel-Ghani, N.T.; El-Chaghaby, G.A.; Helal, F.S. Preparation, characterization and phenol adsorption capacity of activated carbons from African beech wood sawdust. Global Journal of Environmental Science and Management, 2016, 2(3), pp. 209-222.

8. Machado, F.M.; Bergmann, C.P.; Lima, E.C.; Adebayo, M.A.; Fagan, S.B. Adsorption of a textile dye from aqueous solutions by carbon nanotubes. Materials Research, 2014, 17 (Suppl. 1), pp. 153-160.

9. Suteu, D.; Zaharia, C. Sawdust as biosorbent for removal of dyes from wastewaters. Kinetic and Thermodynamic Study. Chemical Bulletin of "Politehnica" University of Timisoara, Romania, 2011, 56(70), pp. 85-88.

10. Prigione, V.; Grosso, I.; Tigini, V.; Anastasi, A.; Varese, G.C. Fungal waste-biomasses as potential low-cost biosorbents for decolorization of textile wastewaters. Water, 2012, 4, pp. 770-784.

11. Owoyokun, T.O.; Sc. M. Biosorption of methylene blue dye aqueous solutions on delonix regia (flamboyant tree) pod biosorbent. The Pacific Journal of Science and Technology; 2009, 10, (2), pp. 872-883.

12. Hameed, B.H.; El-Khaiary, M.I. Removal of basic dye from aqueous medium using a novel agricultural waste material: Pumpkin seed hull. Journal of Hazardous Materials, 2008, 155, pp. 601-609.

13. Bokhari-Taieb Brahimi, H., Faugeron, C.; Hachem, K.; Kaid-Harche, M.; Gloaguen, V. Investigation of parietal polysaccharides from Retama raetam roots. African Journal of Biotechnology, 2015, 14(29), pp. 2327-2334.

14. Djeddi, S.; Karioti, A.; Yannakopoulou, E.; Papadopoulos, K.; Chatter, R.; Skaltsa, H. Analgesic and antioxidant activities of Algerian Retama raetam (Forssk.) Webb \& Berthel Extracts. Records of Natural Products, 2013, 7(3), pp. 169-176.

15. Al-Degs, Y.S.; Sweileh, J.A. Simultaneous determination of five commercial cationic dyes in stream waters using diatomite solid-phase extractant and multivariate calibration. Arabian Journal of Chemistry, 2012, 5, pp. 219-224.

16. El-Qada, E.N.; Allen, S.J.; Walker, G.M. Adsorption of methylene blue onto activated carbon produced from steam activated bituminous coal: a study of equilibrium adsorption isotherm. Chemical Engineering Journal, 2006, 124, pp. 103-110.

17. Ghazi Mokri, H.S.; Modirshahl, N.; Behnajady, M.A.; Vahid, B. Adsorption of C.I. Acid Red 97 dye from aqueous solution onto walnut shell: kinetics, thermodynamics parameters, isotherms. International Journal of Environmental Science and Technology, 2015, 12(4), pp. 1401-1408.

18. Santhi, T.; Manonmani, S.; Smitha, T.; Mahalakshmi, K. Adsorption kinetics of cationic dyes from aqueous solution by bioadsorption onto activated carbon prepared from Cucumis Sativa. Journal of Applied Sciences in Environmental Sanitation, 2009, 4(3), pp. 263-271.

19. Khattria, S.D.; Singh, M.K. Removal of malachite green from dye wastewater using neem sawdust by adsorption. Journal of Hazardous Materials, 2009, 167, pp. 1089-1094.

20. Mahjoub, B.; Ben Brahim, I. Biosorption performance of powdered waste sludge for removal of congo red: Equilibrium and kinetic modeling. Journal of Materials and Environmental Science, 2015, 6(11), pp. 3359-3370. 
21. Marouf-Khelifa, K.; Khelifa, A.; Belhakem, A.; Marouf, R.; Abdelmalek, F.; Addou, A. The adsorption of pentachlorophenol from aqueuous solution onto exchanged Al-MCM-41 materials. Adsorption Science and Technology, 2004, 22 (1), pp. 1-12.

22. Benkhedda, J.; Jaubert, J.N.; Barth, D. Experimental and modeled results describing the adsorption of toluene onto activated carbon. Journal of Chemical and Engineering Data, 2000, 45 pp. 650-653.

23. Riahi, K.; Chaabane, S.; Ben-Thayer, B. A kinetic modeling study of phosphate adsorption onto Phoenix dactylifera L. date palm fibers in batch mode. Journal of Saudi Chemical Society, 2013, doi:10.1016/j.jscs.2013.11.007

24. Maderova, Z.; Baldikova, E.; Pospiskova, K.; Safarik, I.; Safarikova, M. Removal of dyes by adsorption on magnetically modified activated sludge International Journal of Environmental Science and Technology, 2016, doi: 10.1007/s13762-016-1001-8.

25. Subramanyam, B.; Das, A. Linearised and non-linearised isotherm models optimization analysis by error functions and statistical means. Journal of Environmental Health Science \& Engineering, 2014, 12 (92), pp. 1-6.

26. Bajic, Z.J.; Djokc, V.R.; Velickovic, Z.S.; Vuruna, M.M.; Ristic, M.D.; Issa, N.B.; Marinkovic, A.D. Equilibrium; kinetic and thermodynamic studies on removal of $\mathrm{Cd}(\mathrm{II}) ; \mathrm{Pb}(\mathrm{II}) \mathrm{AND} \mathrm{As}(\mathrm{V})$ from wastewater using CARP (Cyprinus Carpio) Scales. Digest. Journal of Nanomaterials and Biostructures, 2013, 8(4), pp. 1581-1590.

27. Alihosseini, A.; Taghikhani, V.; Safekordi, A. A.; Bastani, D. Equilibrium sorption of crude oil by expanded perlite using different adsorption isotherms at 298.15 K. International Journal of Environmental Science and Techology, 2010, 7(3), pp. 591-598.

28. Wang, L.; Zhang, J.; Zhao, R.; Li, Y.; Li, C.; Zhang, C. Adsorption of Pb(II) on activated carbon prepared from Polygonum orientale Linn.: Kinetics; isotherms; pH; and ionic strength studies. Bioresource Technology, 2010, 101(15), pp. 5808-5814.

29. Udoji, I.A.; Etim, E.E. Dynamics of $\mathrm{M}^{\mathrm{x}+}$ salts of fatty acids adsorption onto metallic ores. International Journal of Environmental Science and Development, 2015, 6(3), pp. 205-210.

30. Gulipall, C.S.; Prasad, B.; Wasewar, K.L. Batch study; equilibrium; and kinetics of adsorption of selenium using Rice Husk Ash (RHA). Journal of Engineering Science and Technology, 2011, 6(5), pp. 586-605.

31. Chouchane, T.; Yahi, M.; Boukari, A.; Balaska, A.; Chouchane, S. Adsorption of the copper in solution by the kaolin. Journal of Materials and Environmental Science, 2016, 7(8), pp. 2825-2842. (in French).

32. Ezechi, E.H.; Kutty, S.R.M.; Malakahmad, A.; Isa, M.H. Characterization and optimization of effluent dye removal using a new low cost adsorbent: Equilibrium, kinetics and thermodynamic study. Process Safety and Environmental Protection. 2015, 98, pp. 16-32.

33. Dahri, M.K.; Kooh, M.R.R.; Lim, L.B.L. Water remediation using low cost adsorbent walnut shell for removal of malachite green: Equilibrium; kinetics; thermodynamic and regeneration studies. Journal of Environmental Chemical Engineering, 2014, 2(3), pp.1434-1444

34. Baek, M.H.; Ijagbemi, C.O.; Kim D.S. Removal of Malachite Green from aqueous solution using degreased coffee bean. Journal of Hazardous Materials, 2010, 176, pp. 820-828.

35. Shilpi, A.; Shivhare, U.S.; Basu, S. Supercritical $\mathrm{CO}_{2}$ extraction of compounds with antioxidant activity from fruits and vegetables waste. Focusing on Modern Food Industry, 2013, 2(1), pp. 43-62.

36. Kyzas, G.Z.; Lazaridis, N.K.; Mitropoulos, A.C. Removal of dyes from aqueous solutions with untreated coffee residues as potential low-cost adsorbents: Equilibrium; reuse and thermodynamic approach. Chemical Engineering Journal, 2012, 189- 190, pp.148-159.

37. Secula, M.C.; Cagnon, B.; Creţescu, I.; Diaconu, M.; Petrescu, S. Removal of an acid dye from aqueous solutions by adsorption on a commercial granular activated carbon: equilibrium, kinetic and thermodynamic study. Scientific Study \& Research - Chemistry and Chemical Engineering, Biotechnology, Food Industry, 2011, 12(4), pp. 307-322.

38. Santhi, T.; Manonmani, S.; Smitha, T. Kinetics And Isotherm Studies On Cationic Dyes Adsorption Onto Annona Squmosa Seed Activated Carbon. International Journal of Engineering Science and Technology, 2010, 2(3), pp. 287-295.

39. Oboh, I.O.; Aluyor, E.O.; Audu, T.O.K. Second-order kinetic model for the adsorption of divalent metal ions on Sida acuta leaves. International Journal of Physical Sciences, 2013, 8(34), pp. 1722-1728.

40. Abuh, M.A.; Akpomie, G.K.; Nwagbara, N.K.; Abia-Bassey, N.; Ape, D.I.; Ayabie, B.U. Kinetic rate equations application on the removal of copper (II) and zinc (II) by unmodified lignocellulosic fibrous layer of palm tree trunk single component system studies. International Journal of Basic and Applied Science, 2013, 1(4), pp. 800-809. 